
History Research

Reseña

\section{Mercedes Fernández-Paradas y Carlos Larrinaga (coords.). El impacto de la Guerra Civil española en el sector tercia- rio. Granada, Comares, 2019, 172 pp. ISBN: 9788490458358.}

El sujeto de análisis del trabajo coordinado por Fernández Paradas y Larrinaga es un sector, el terciario, que en las últimas décadas ha recibido una creciente atención que se ha manifestado notablemente en los equipamientos urbanos. Partiendo de la línea argumental de la modernización que había experimentado la sociedad española desde finales del siglo xIx, de la que el sector terciario fue partícipe fundamental, tratan de evaluar el impacto que el conflicto tuvo en distintos frentes: el sector del gas, la industria eléctrica, parte del sector financiero, el transporte y el turismo.

El libro se estructura en siete capítulos, comenzando con una síntesis histórica y memoria, en la que Eduardo González Calleja dibuja el contexto general, reflexionando sobre las interpretaciones que se han aducido acerca de las causas del conflicto armado, el golpe y las operaciones militares. Se trata de un acercamiento histórico, no económico, en el que aporta el encuadre político-bélico. El autor enuncia sucintamente los principales elementos sobre los que se asentó la evolución política y social en las dos zonas en que quedó dividido el país. Finaliza con una recapitulación sobre el final de la guerra y el comienzo del exilio, y con la idea de recuperar la memoria histórica entre la ciudadanía.

En el segundo capítulo, Mercedes Fernández Paradas analiza el sector del gas, adoptando un enfoque regional, sin perder de vista la comparación con otros países de la Europa latina y con Gran Bretaña. Examina el tejido empresarial existente en vísperas de la contienda, caracterizando las compañías, el número de factorías y su localización. Proporciona cifras sobre la trayectoria decreciente de la producción de gas y de los subproductos obtenidos en las fábricas situadas a uno y otro lado del frente bélico, demostrando una peor evolución en el territorio republicano como consecuencia de las mayores dificultades para el suministro de hulla desde 1937. El consumo de gas experimentó una tendencia similar de caída, especialmente en su calidad, como resultado del uso de materias primas inadecuadas, de las averías y las dificultades de mantenimiento de fábricas y redes de distribución. Por último, enumera las principales dificultades que debieron afrontar las empresas: división de sus activos, escasez de materias primas y personal, y los daños sufridos en las instalaciones, aunque la guerra no ocasionase destrozos de consideración en la infraestructura gasista.

Anna Maria Aubanell estudia la industria eléctrica. Parte de un sucinto análisis del sector antes de la guerra, incluyendo cifras de producción durante 1930-1940. Debido a la inexistencia de una red eléctrica nacional, explora las principales regiones consumidoras. En el País Vasco-Navarro producción y con- sumo se hallaban separados, por lo que se vio condicionado por las fuentes de aprovisionamiento: Guipúzcoa (abastecida desde instalaciones próximas) no se vio excesivamente perjudicada, mientras Vizcaya (dependiente de territorios alejados) vio disminuir su suministro. En Cataluña, en donde la generación se concentraba en los Pirineos, el suministro no sufrió trastornos, independientemente de si las empresas fueron dirigidas (como ocurrió en los primeros años) por los trabajadores o si fueron incautadas por los rebeldes. El mercado de Madrid, conectado con el Levante, no se vio afectado; al contrario, su consumo creció, sobre todo en el segmento doméstico. Finalmente, Andalucía se dividió en dos zonas, lo que provocó problemas de desconexión a algunas de las empresas dominantes. En definitiva, una variedad de situaciones en las que el denominador común fue la caída de la demanda (sobre todo industrial) mayor que la producción, ya que las empresas operaron con relativa normalidad.

Juan Manuel Matés inspecciona la actuación del Banco de Crédito Local de España, desde su creación (1925) hasta el final de la guerra, encuadrándolo dentro del estado del sector bancario. Arranca con su gestación, dentro del contexto expansivo del sector financiero durante la posguerra mundial. A pesar de que su aparición generó grandes expectativas para sus potenciales clientes (las corporaciones locales), su concreción real se alejó de los objetivos perseguidos. Repasa los efectos de la crisis de 1929 y del advenimiento de la Segunda República sobre el crecimiento de la entidad, que amenazaron incluso su continuidad. Seguidamente, constata los dañinos efectos de la sublevación sobre la banca, la pugna que se desencadenó en cada bando por intentar implantar un sistema financiero adecuado a sus intereses, así como un breve balance sobre los resultados empresariales. El siguiente paso es cotejar el devenir del Banco durante la guerra, concluyendo con una referencia a la suerte que corrieron sus principales promotores durante esos años.

Fernando Lerma y Leonardo Caruana indagan en el sector asegurador. La primera parada es en su marco jurídico entre 1908 (primera ley general de seguros) y 1939, y en su avance, gracias al desembarco en nuestro país del capital extranjero, que dejó una profunda huella en este negocio. La guerra significó un duro golpe para las empresas, tanto las situadas en el bando republicano (donde la gestión pasó a manos del Gobierno) como en el nacional (donde se mantuvo la iniciativa privada). Lo excepcional de la situación complicaba tanto los cobros de las primas como los pagos. A pesar de ello, el volumen de primas consiguió incrementarse durante este período.

Rafael Barquín se ocupa de las principales componentes de los transportes, poniendo de relieve que, a pesar de la inicial superioridad republicana, la priorización de objetivos no militares inclinó la balanza del lado nacional. El sistema ferroviario experimentó una fuerte alteración, prevaleciendo el trans- 
porte por encima de la gestión empresarial. Pero la concepción organizativa de los sublevados fue más eficaz, ya que mantuvieron la estructura de gestión de las empresas, priorizando los objetivos bélicos, mientras en el bando republicano carecieron de un planeamiento integral: si bien se incautaron de las grandes compañías, el Ejército no fue el encargado de su supervisión, anteponiéndose aspectos de carácter revolucionario. La marina mercante fue rápidamente requisada, con diferencias entre los contendientes, que provocaron que su funcionamiento en la zona republicana fuese descoordinado y menos eficiente. En lo relativo al transporte por carretera (y, con matices, en la aviación civil), Barquín señala que su regulación fue similar en ambos territorios, y que el deterioro ocasionado por el conflicto fue menos grave del que cabría esperar.

El último sector, el turístico, es responsabilidad de Carlos Larrinaga. Tras una introducción, en la que evidencia su desarrollo durante el primer tercio del siglo, ahonda en el impacto del alzamiento en un ramo que ya atravesaba una coyuntura crítica. La guerra desestructuró el sector desde un punto de vista organizativo (asociaciones, operadores, intermediarios, compañías de comunicaciones, industria hotelera, etc.), hundiendo las cifras de visitantes y los resultados económicos, aunque con distintas realidades, ya que en las provincias ocupadas por el ejército franquista el comportamiento fue más positivo. La novedad fue el surgimiento de nuevas modalidades de turismo: los viajes espontáneos a los frentes de guerra; los viajes para conocer cómo vivían los españolas y acudir a los escenarios de guerra, que formaban parte de una estrategia de guerra psicológica con objetivos propagandísticos, y las denominadas rutas de guerra, viajes colectivos mercantilizados, organizados oficialmente por el régimen franquista.

Jesús Mirás Araujo Universidade da Coruña

https://doi.org/10.33231/j.ihe.2020.03.010 